\title{
Strategic planning for tourism industry using SWOT and QSPM
}

\author{
Hamid Abya $^{a^{*}}$, Mohammad Mehdi Nasiri Khalilib*, Mohsen Ebrahimic and Ali Movahed ${ }^{\mathrm{a}}$
}

${ }^{a}$ Department of Geography, University of Kharazmi, Tehran, Iran

${ }^{b}$ PhD student, Department of Geography and Urban Planning, Islamic Azad University, Semnan Branch, Semnan, Iran ${ }^{c}$ Department of Management, Tarbiat Modarres University, Tehran, Iran

\section{H R O N C L E A B S T R C T}

\begin{tabular}{l}
\hline Article history: \\
Received September 28, 2014 \\
Accepted 15 January 2015 \\
Available online \\
January 23 2015 \\
\hline Keywords: \\
Tourism \\
Galugah \\
SWOT \\
QSPM
\end{tabular}

\section{Introduction}

Tourism has its impact on economic, cultural and political issues (Simpson, 2001). Tourism may create job, increase foreign travel demand as well as security in the country and makes it a reliable source of income for local residences (Inskeep, 1991). Many countries collect income from tourism than any other industries such as natural resources, etc. Tourism also plays an essential role in encouraging investment in infrastructure, generating revenue for the state and its direct and indirect job involvement across the world (Heath \& Wall, 1991). The development of this tourism in industrialized countries may diversify income and reduce the imbalance in the economy (Getz, 1983). In several developing countries, it generates the opportunity for exports, productions and job creation. Moreover, the advantages of tourism

*Corresponding author.

E-mail addresses: h_abya@yahoo.com (H. Abya)

(c) 2015 Growing Science Ltd. All rights reserved. doi: $10.5267 /$ j.msl.2015.1.009

\begin{abstract}
Tourism plays essential role in today’s economy and Iran has good position of tourism sources such as natural, historical, cultural, etc., although, these sources have not been utilized, properly. One of regions which have many potentiality and capabilities for developing Tourism in natural aspect is district and city of Galugah. The purpose of this study is to provide strategic sustainable tourism development in this city. The study uses three techniques namely; Quantitative Strategic Planning Matrix (QSPM) and strengths, weaknesses, opportunities and threats (SWOT) to determine necessary guidelines for development of tourism in the city of Galugah, Iran. The study first uses SWOT to categorize different factors and then QSPM is applied to prioritize various factors. The results of this study show that presenting methods in initial process and analyzing assessment matrix of T2 external and internal factors i.e. pollution of environment and river and extinction of plants species by result of pollution and $\mathrm{O} 2$ i.e. suitable climate for developing natural Tourism efforts in summer have been recognized as most priority factors among external factors. Intense cold of region in summer (W3) and most priority factors among internal factors on Tourism development of Galugah city.
\end{abstract}


are not limited to economic interest but it creates an opportunity to introduce the culture of a country to other countries. Tourism characteristics of each location in affected by the importance of validity, nature, role and function of a variety of religious, cultural, recreational, commercial and general attractions of its location (Allen, 1998). Moreover, it has been influenced by the characteristics of the social, cultural (religious belief) and local residents and tourism economy. Galugah is a county in Mazandaran Province in Iran and Galugah is the capital of the county, which is separated from Behshahr County in 2005. At the 2006 census, the county's population was 39,450 people consisted of 10,365 families. Fig. 1 shows some of the remarkable regions of this city.
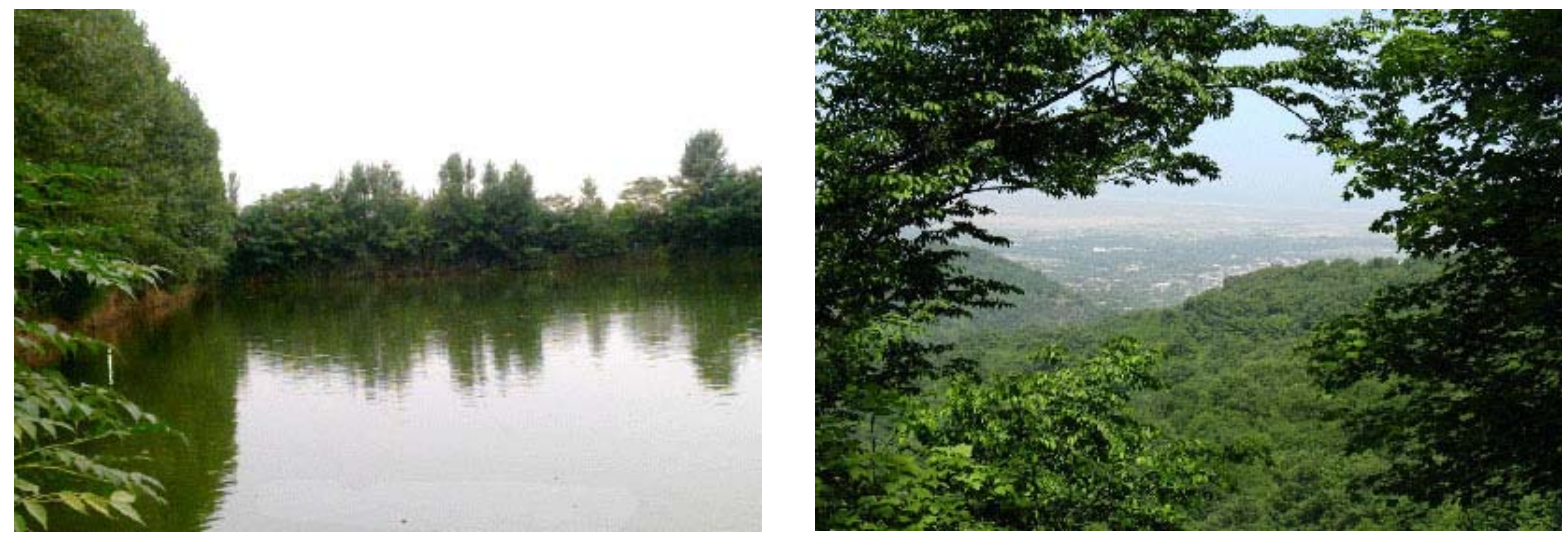

Fig. 1. The region of Galugah

The region has outstanding natural attractions, which could preserve a good potential for development of tourism industry (Pak \& Farajzadeh, 2007; Nouri et al., 2008; Farhoodi et al., 2009).

\section{The proposed study}

The purpose of this study is to provide strategic assessment and optimization strategies for development of tourism industry to reach sustainable tourism development in city of Qom metropolis. The study uses three techniques namely; Quantitative Strategic Planning Matrix (QSPM), integrated environmental assessment (IEA) and strengths, weaknesses, opportunities and threats (SWOT) for the implementation of the study. The study first uses SWOT to categorize different factors, IEA is applied to determine internal as well as external factors and finally QSPM is applied to prioritize various factors.

\subsection{SWOT analysis}

A SWOT analysis is a structured planning technique applied to make necessary evaluation on the strengths, weaknesses, opportunities and threats integrated in a particular problem. A SWOT analysis can be also applied for city development, which involves specifying the objective of the business venture or project and detecting the internal and external factors, which are considered as advantage/disadvantage to reach that objective. The following summarizes various perspectives of SWOT,

- Strengths: characteristics of the business, which provide an advantage over others,

- Weaknesses: characteristics that pose the business at a disadvantage compared with others,

- Opportunities: elements the project could exploit to its advantage,

- Threats: elements in the environment, which could generate trouble for the business.

Identification of SWOTs is essential because they can inform later steps in planning to reach the objective (See Fig. 2). 


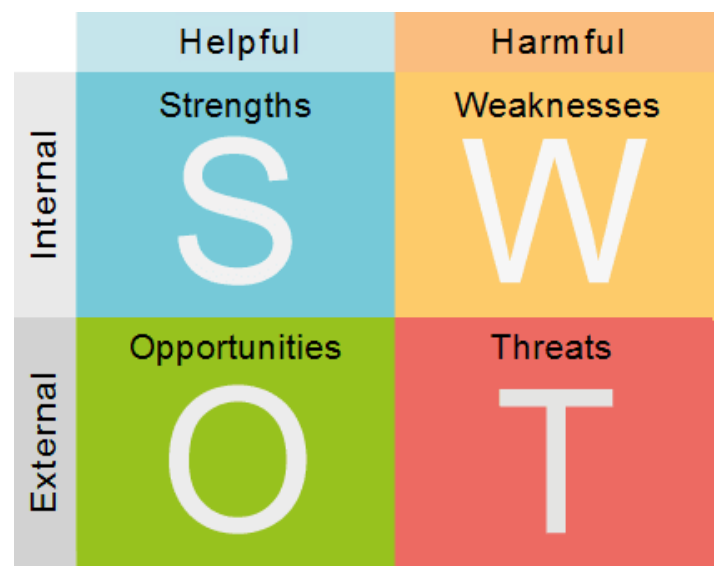

Fig. 2. The structure of SWOT

The analysis consists of two major items of external and internal factors. Table 1 demonstrates the summary of opportunities and threats associated with external factors. Let $R_{i j}$ be the score of factor $j$ in group $i$, $S_{i}$ be the Likert scale point given to group $i$ and $F_{i}$ be the frequency of each group. Therefore, the score given to each factor is measured as follows,

$R_{i j}=\sum F_{i} S_{i}$.

In addition, we may normalize Eq. (1) as follows,

$$
Y_{i j}=\frac{R_{i j}}{\sum R i j} \text {. }
$$

The proposed study designed a questionnaire in Likert scale and distributed it among some experts and using Eq. (1) and Eq. (2), the study has calculated the weights of internal and external factors.

\section{Table 1}

The summary of the weights of external factors

\begin{tabular}{|c|c|c|c|c|c|}
\hline & & Score & $\%$ & Point & Final \\
\hline \multirow{3}{*}{ Environmental factors } & O1 & 118 & 0.039 & 4 & 0.156 \\
\hline & $\mathrm{O} 2$ & 128 & 0.042 & 4 & 0.17 \\
\hline & $\mathrm{O} 3$ & 119 & 0.039 & 4 & 0.158 \\
\hline Infrastructures & $\mathrm{O} 4$ & 121 & 0.04 & 4 & 0.16 \\
\hline \multirow{2}{*}{ Socio-cultural } & $\mathrm{O} 5$ & 118 & 0.039 & 2 & 0.078 \\
\hline & O6 & 117 & 0.039 & 2 & 0.078 \\
\hline \multirow{3}{*}{ Economic } & $\mathrm{O} 7$ & 116 & 0.038 & 2 & 0.077 \\
\hline & O8 & 125 & 0.041 & 3 & 0.124 \\
\hline & O9 & 124 & 0.041 & 3 & 0.123 \\
\hline \multirow{3}{*}{ Institutional management } & $\mathrm{O} 10$ & 120 & 0.04 & 2 & 0.08 \\
\hline & O11 & 117 & 0.039 & 3 & 0.116 \\
\hline & $\mathrm{O} 12$ & 125 & 0.041 & 2 & 0.083 \\
\hline \multirow{5}{*}{ Environmental } & $\mathrm{T} 1$ & 97 & 0.032 & 3 & 0.096 \\
\hline & $\mathrm{T} 2$ & 130 & 0.043 & 4 & 0.172 \\
\hline & T3 & 120 & 0.04 & 3 & 0.119 \\
\hline & $\mathrm{T} 4$ & 99 & 0.033 & 3 & 0.098 \\
\hline & T5 & 107 & 0.035 & 3 & 0.106 \\
\hline Infrastructure & T6 & 123 & 0.041 & 3 & 0.122 \\
\hline Socio-cultural & T7 & 101 & 0.033 & 2 & 0.067 \\
\hline \multirow{3}{*}{ Economic } & T8 & 91 & 0.03 & 1 & 0.03 \\
\hline & Т9 & 84 & 0.028 & 1 & 0.028 \\
\hline & $\mathrm{T} 10$ & 98 & 0.032 & 1 & 0.032 \\
\hline \multirow{5}{*}{ Institutional management } & T11 & 103 & 0.034 & 2 & 0.068 \\
\hline & $\mathrm{T} 12$ & 118 & 0.039 & 1 & 0.039 \\
\hline & $\mathrm{T} 13$ & 120 & 0.04 & 3 & 0.119 \\
\hline & $\mathrm{T} 14$ & 102 & 0.034 & 2 & 0.068 \\
\hline & T15 & 94 & 0.031 & 2 & 0.062 \\
\hline
\end{tabular}


Table 2

The summary of the weights of external factors

\begin{tabular}{|c|c|c|c|c|c|}
\hline & & Score & $\%$ & Point & Final \\
\hline \multirow{6}{*}{ Environment } & S1 & 127 & 0.041 & 4 & 0.162 \\
\hline & S2 & 118 & 0.038 & 4 & 0.151 \\
\hline & S3 & 121 & 0.039 & 4 & 0.154 \\
\hline & S4 & 109 & 0.035 & 3 & 0.104 \\
\hline & S5 & 130 & 0.041 & 4 & 0.166 \\
\hline & S6 & 120 & 0.038 & 4 & 0.153 \\
\hline Infrastructure & S7 & 121 & 0.039 & 2 & 0.077 \\
\hline \multirow{3}{*}{ Socio-cultural } & S8 & 102 & 0.033 & 2 & 0.065 \\
\hline & S9 & 104 & 0.033 & 2 & 0.066 \\
\hline & $\mathrm{S} 10$ & 112 & 0.036 & 2 & 0.071 \\
\hline \multirow{3}{*}{ Economic } & S11 & 125 & 0.04 & 2 & 0.08 \\
\hline & S12 & 124 & 0.04 & 2 & 0.079 \\
\hline & $\mathrm{S} 13$ & 106 & 0.034 & 2 & 0.068 \\
\hline Institutional & S14 & 118 & 0.038 & 2 & 0.075 \\
\hline \multirow{3}{*}{ Environment } & W1 & 120 & 0.038 & 3 & 0.115 \\
\hline & W2 & 111 & 0.035 & 3 & 0.106 \\
\hline & W3 & 134 & 0.043 & 4 & 0.171 \\
\hline \multirow{3}{*}{ Infrastructure } & W4 & 121 & 0.039 & 3 & 0.116 \\
\hline & W5 & 118 & 0.038 & 2 & 0.075 \\
\hline & W6 & 125 & 0.04 & 3 & 0.12 \\
\hline \multirow{2}{*}{ Socio-cultural } & W7 & 117 & 0.037 & 2 & 0.075 \\
\hline & W8 & 100 & 0.032 & 1 & 0.032 \\
\hline \multirow{5}{*}{$\begin{array}{l}\text { Institutional } \\
\text { management }\end{array}$} & W9 & 102 & 0.033 & 1 & 0.033 \\
\hline & W10 & 112 & 0.036 & 2 & 0.071 \\
\hline & W11 & 109 & 0.035 & 1 & 0.035 \\
\hline & W12 & 108 & 0.034 & 1 & 0.034 \\
\hline & W13 & 121 & 0.039 & 2 & 0.077 \\
\hline
\end{tabular}

Table 3 and Table 4 demonstrate details of external and internal factors.

Table 3

The summary of external factors

\begin{tabular}{|c|c|c|c|}
\hline Priority & Score & Code & Opportunity and Treats \\
\hline 1 & 0.172 & T2 & Environment and water contamination and the loss of plants and animals species because of pollution \\
\hline 2 & 0.170 & $\mathrm{O} 2$ & Existence of good weather for normal development of tourism activities in summer \\
\hline 3 & 0.160 & $\mathrm{O} 4$ & Strengthening and development of road infrastructure and traffic \\
\hline 4 & 0.158 & $\mathrm{O} 3$ & Possible development of tourism activates such as hiking, biking and winter sports \\
\hline 5 & 0.156 & O1 & Use of natural resources for tourism development and introduction of an important tourism centers \\
\hline 6 & 0.124 & $\mathrm{O} 8$ & Commitment for having a production plants for sand can lead the way for the creation of sustainable income \\
\hline 7 & 0.123 & O9 & Increase Aboriginal employment with tourists \\
\hline 8 & 0.122 & T6 & Road accidents and fatalities to tourists \\
\hline 9 & 0.119 & T3 & Increased consumption of fossil fuels due to severe cold region \\
\hline 10 & 0.119 & T13 & Existence of illegal hunters and risk of loss of species \\
\hline 11 & 0.116 & O11 & Increased support to planning authorities in the city due to its high capacity of Ecotourism \\
\hline 12 & 0.106 & T5 & Improper disposal of domestic wastewater production and workshop \\
\hline 13 & 0.098 & T4 & Natural disasters (earthquakes, floods, landslides and landslides) \\
\hline 14 & 0.096 & T1 & $\begin{array}{l}\text { Environmental damage caused by the accumulation and disposal of attractions and improper waste and excessive entry } \\
\text { of tourists }\end{array}$ \\
\hline 15 & 0.083 & $\mathrm{O} 12$ & Promoting human resources to raise awareness of local residents about tourism issues \\
\hline 16 & 0.080 & $\mathrm{O} 10$ & Cultivation of medicinal plants through the formation of cooperatives \\
\hline 17 & 0.078 & O5 & $\begin{array}{l}\text { Taking advantage of the participation and interaction between NGOs and government agencies to protect the } \\
\text { environment and improve tourism }\end{array}$ \\
\hline 18 & 0.078 & O6 & Paying more attention to the handy crafts and customs and cultural heritage protection \\
\hline 19 & 0.077 & $\mathrm{O} 7$ & Creating favorable conditions for economic growth and development of nature-based tourism \\
\hline 20 & 0.068 & T11 & Dam under construction, named Golurd, causes a large part of the fertile pastures goes underwater \\
\hline 21 & 0.068 & T14 & Building dams and damaging the eco-tourism area \\
\hline 22 & 0.067 & T7 & The loss of native culture and effects of tourists' cultures on people \\
\hline 23 & 0.062 & T15 & Lack of timely and appropriate assistance to tourists who have been suffering from car accidents and natural disasters \\
\hline 24 & 0.039 & T12 & Immigration of local residences to the region due to air pollution from major cities \\
\hline 25 & 0.032 & T10 & Reduction in government funding for tourism development \\
\hline 26 & 0.030 & T8 & Construction of non-residential private sector \\
\hline 27 & 0.028 & T9 & Lack of investment in the public sector according to accommodation and tourism facilities \\
\hline
\end{tabular}


Table 3

The summary of internal factors

\begin{tabular}{|c|c|c|c|}
\hline Priority & Score & Code & Opportunity and treats \\
\hline 1 & 0.171 & W3 & Severe cooling snowy mountain in winter \\
\hline 2 & 0.166 & S5 & Existence of exclusive entertainment places such as Toska Cheshme \\
\hline 3 & 0.162 & S1 & Located in nice weather \\
\hline 4 & 0.154 & S3 & $\begin{array}{l}\text { Existence of certain natural environment (rivers, streams, springs and rare animal species and plant species with } \\
\text { therapeutic properties) }\end{array}$ \\
\hline 5 & 0.153 & S6 & Virgin nature and the existence of rare and morphological pictures \\
\hline 6 & 0.151 & S2 & Beautiful landscapes and protected areas with diverse wildlife and vegetation \\
\hline 7 & 0.120 & W6 & Poor public transport and roads due to the mountainous region \\
\hline 8 & 0.116 & W4 & Dangerous mountain roads \\
\hline 9 & 0.115 & W1 & Higher elevations with steep slopes \\
\hline 10 & 0.106 & W2 & Danger of snow fall \\
\hline 11 & 0.104 & S4 & Recreational and sports like mountaineering and cycling \\
\hline 12 & 0.080 & S11 & Interest of local residence for fish farm under a completely safe and appropriate environmental conditions \\
\hline 13 & 0.079 & S12 & Availability of visiting natural attractions free of charge \\
\hline 13 & 0.077 & S7 & Development of infrastructure such as gas, electricity and telecommunication systems \\
\hline 14 & 0.077 & W13 & Agricultural land use changes \\
\hline 15 & 0.075 & S14 & Approval of the city tourism plan \\
\hline 16 & 0.075 & W5 & Deficient and inadequate accommodation facilities \\
\hline 17 & 0.075 & W7 & Lack of cultural and health issues by tourists (waste discharge and river level range) \\
\hline 18 & 0.071 & S10 & Availability of holy shrine places such as BiBiZeynab \\
\hline 19 & 0.071 & W10 & Lack of health centers \\
\hline 20 & 0.068 & S13 & Existence of young people as active labor \\
\hline 21 & 0.066 & S9 & History and culture of the region, such as poets and writers in this area \\
\hline 22 & 0.065 & S8 & Existence of attractions and monuments \\
\hline 23 & 0.035 & W11 & Lack of guide for tourists \\
\hline 24 & 0.034 & W12 & Bad publicity and lack of proper introduction attraction \\
\hline 25 & 0.033 & W9 & The absence of guards in protected areas \\
\hline 26 & 0.032 & W8 & Destruction of agricultural lands and waste emissions by tourists \\
\hline
\end{tabular}

\section{Discussion and Conclusion}

Based on the results gathered from Table 3 and Table 4, we have performed a brain storming discussion among some experts and tried to extract the SWOT matrix. Table 5 shows details of our findings.

\section{Table 5}

The summary of SWOT

\begin{tabular}{|c|c|}
\hline Review strategy (WO) & Aggressive strategy (SO) \\
\hline $\begin{array}{l}\text { Wo1: Developing appropriate communication network, due to the lack } \\
\text { of communication network and the expansion of public transport in the } \\
\text { area } \\
\text { Wo2: Revision of the publicity and awareness activities in the media and } \\
\text { creating websites appropriate to introduce eco-tourism attractions and } \\
\text { capabilities, religious and cultural aspects of the city (w4 -w6 -o4) } \\
\text { Wo3: Improvement of tourism products and the joint venture public- } \\
\text { private sector (w5 -o1- o5 -o7 -o11) } \\
\text { Wo4: Creating training programs (w11 -w12 -o1 -o2 -o7) } \\
\text { Wo5: Creating appropriate regulations in order to protect the } \\
\text { environment and to revise the regulations of urban land (w8 -w13 -o1- } \\
\text { o2 -o11) }\end{array}$ & $\begin{array}{l}\text { So1: Investment and greater emphasis on cultural, religious and } \\
\text { historical places of this beautiful place to attract more tourists ( } \\
\text { s8 -s9 -s10 -o6) } \\
\text { So2: Incentives for nature Battalion traveled to the region through the } \\
\text { construction of recreational and travel services (s1 -s2 -s3 -s5 -s6-o1 -o2) } \\
\text { So3: Proper use of the potentials of eco-tourism attractions and tourism } \\
\text { as the main substrate city (s1 -s2 -s3 -s5 -s6 -o1 -o2) } \\
\text { So4: Development of tourism resources and the establishment of eco- } \\
\text { tourism tours in the city (s2 -s3 -s5 -s6 -o1-o2 -o4) } \\
\text { So5: Using the existing potential to develop the sport of mountain } \\
\text { climbing and sport tourism (s1 -s2 -s3 -s4- s5 -s6 -o1 -o2 -o3) }\end{array}$ \\
\hline Defensive strategy (WT) & Diversified strategy (ST) \\
\hline $\begin{array}{l}\text { Wt1: The negative effects of tourism development and try to minimize } \\
\text { these effects (w7-w8 -w13 -t1-t2-t5-t11- t7 -t12 -t14) } \\
\text { Wt2: Promoting the health and development of these centers in the city } \\
\text { (w7-w10 -t5 -t6-t15) } \\
\text { Wt3: Having meetings and seminars by organizations responsible for } \\
\text { developing ecotourism facilities and privileges invested in construction } \\
\text { of hotels, residential complexes and recreational facilities (s5 -w11-w12- } \\
\text { t8-t9-t10) } \\
\text { Wt4: Having an appropriate rules and regulations to protect } \\
\text { environment (w7 -w8-w13-t1-t2-t5-t11-t14) }\end{array}$ & $\begin{array}{l}\text {-St1 Development of information and education services and tourism } \\
\text { information about the destruction of the natural environment ( } \mathrm{s} 2-\mathrm{s} 3 \text { - } \\
\mathrm{s} 5 \text {-s6-t1 -t2 -t5) } \\
\text { St2 Increase funding for the development of specialized tourist } \\
\text { attractions (s1- s2 -s3 -s4 -s5 -s6 -t10) } \\
\text { St3: Creation of new job opportunities based on natural potentials and } \\
\text { rich local culture with the aim of protecting the region's natural and } \\
\text { cultural identity (-s9 -s8 s10 -s13- -t1 t2- t14 - t11- t7-t5) } \\
\text { St4 : Prevent environmental degradation and the loss of vegetation and } \\
\text { animal species (s2 -s3- s5 -s6 -t } 1 \text {-t2-t5 -t11 -t13 -t14) }\end{array}$ \\
\hline
\end{tabular}

Based on the scores given to each action, we summarize our SWOT strategic planning in Table 6. As we can observe from the results of Table 4, the most important factors are concentrated on environmental and natural factors affecting tourism development. In fact, 17 out of 52 factors are associated with this item, which show the relative importance of environmental factors. 


\section{Table 6}

The summary of different actions and strategies

\begin{tabular}{lcccccccccccc}
\hline Priority & Action & Score & Action & Score & Action & Score & Action & Score & Action & Score & Action & Score \\
\hline First & St3 & 2.61 & So3 & 2.45 & So4 & 2.24 & So5 & 2.13 & St4 & 2.07 & St1 & 2 \\
Second & So3 & 1.94 & Wt1 & 1.71 & Wo2 & 1.67 & St2 & 1.62 & St3 & 1.61 & Wt4 & 1.6 \\
Third & Wo1 & 1.36 & Wo5 & 1.35 & Wo3 & 1.57 & Wo4 & 1.54 & Wt3 & 1.18 & Wt2 & 1.17 \\
\hline
\end{tabular}

The biggest advantages of the city include virgin natural resources and beautiful landscape. Therefore, proper use of the potentials of eco-tourism attractions must be considered, more significantly. The weakness point of the survey is associated with poor management of the city. In our survey, 12 out of 15 threats are associated with external factors and they are mostly related to management of the city. The biggest external factors are environment pollution and lack of attention for taking care of the city.

Results of this research show that presenting methods in initial process and analyzing assessment matrix of T2 external and internal factors i.e. pollution of environment, river and extinction of plants species by result of pollution and $\mathrm{O} 2$ i.e. suitable climate for developing natural Tourism efforts in summer have been recognized as the most priority factors among external factors. Intense cold weather in region during the season of summer (W3) and existence of unique amusement places (S5) such as Amarg were recognized as effective and most priority factors among internal factors on Tourism development of Galugah city. Presenting methods of second process showed final score of assessment matrix in internal and external factors in this manner: 2.53-2.63. So, it shows that Tourism position of Galugah city was normal. According to four parts assessment matrix, importance and priority of SO methods was defined towards other methods in this process. Presenting methods of the third process have shown that comparison of total grades for attractiveness of methods and ST3 method i.e. initiating new occupational opportunities on the basis of natural potentials and rich culture of regions inhabitants by protecting region cultural identity and nature have maintained the greatest scores in this process.

\section{References}

Allen, L. R., Long, P. T., Perdue, R. R., \& Kieselbach, S. (1988). The impact of tourism development on residents' perceptions of community life. Journal of travel research, 27(1), 16-21.

Farhoodi, R., Gharakhlou-N, M., Ghadami, M., \& Khah, M. P. (2009). A critique of the prevailing comprehensive urban planning paradigm in Iran: The need for strategic planning. Planning Theory, 8(4), 335-361.

Freeman, E. H. (1992). A knowledge-based approach to strategic planning. InLogic Programming in Action (pp. 109-117). Springer Berlin Heidelberg.

Getz, D. (1983). Capacity to absorb tourism: Concepts and implications for strategic planning. Annals of Tourism Research, 10(2), 239-263.

Heath, E., \& Wall, G. (1991). Marketing tourism destinations: a strategic planning approach. John Wiley \& Sons, Inc.

Inskeep, E. (1991). Tourism planning: an integrated and sustainable development approach. Van Nostrand Reinhold.

Nouri, J., Karbassi, A. R., \& Mirkia, S. (2008). Environmental management of coastal regions in the Caspian Sea. International Journal of Environmental Science \& Technology, 5(1), 43-52.

Pak, A., \& Farajzadeh, M. (2007). Iran's integrated coastal management plan: Persian Gulf, Oman Sea, and southern Caspian Sea coastlines. Ocean \& Coastal Management, 50(9), 754-773.

Simpson, K. (2001). Strategic planning and community involvement as contributors to sustainable tourism development. Current Issues in Tourism, 4(1), 3-41. 